\title{
Doğru Akım Motor Sürücüleri için PI Parametrelerinin Simbiyotik Organizmalar Arama Algoritması ile Optimal Ayar1
}

\author{
Emre ÇELIK ${ }^{1} *$, Nihat ÖZTÜRK \\ ${ }^{1}$ Teknoloji Fakültesi Elektrik-Elektronik Mühendisliği, Gazi Üniversitesi, Ankara, Türkiye \\ emrecelik@gazi.edu.tr, ozturk@gazi.edu.tr \\ (Geliş/Received:15.02.2017; Kabul/Accepted:01.06.2017) \\ DOI: $10.17671 /$ gazibtd. 331044
}

\begin{abstract}
Özet- Doğru akım (DA) motorları ekonomik olmaları yanında denetimlerinin basitliği ve iyi derecedeki moment-hız karakteristiklerinden dolayı hem endüstriyel uygulamaların hem de günlük yaşantımızın önemli elektrik makinalarıdır. Denetimlerinde kullanılan oransal+integral (PI) denetleyici parametrelerin doğru bir şekilde ayarı zor olmakla beraber sistemin performansı ve kararlılı̆ı açısından önemli bir yer tutmaktadır. Bu çalışmada PI katsayılarının optimizasyonu için dayanıklı ve güçlü simbiyotik organizmalar arama (SOS) algoritmasına dayalı yeni bir alternatif çözüm sunulmaktadır. Çalışmada genetik algoritma (GA) ile klasik Ziegler-Nichols (Z-N) yöntemi kullanılarak elde edilen cevapların geçici durum analizleri yapılarak sistemin yükselme zamanı, yerleşme zamanı ve maksimum aşım değerleri karşılaştırılmıştır. Aynı zamanda ortaya konulan yaklaşımın değişik parametre durumunda gürbüzlük analizi gerçekleştirilmiştir. Gerçek bir endüstriyel motora ait parametreler ile $\mathrm{C}$ dili kullanılarak gerçekleştirilen benzetim sonuçlarına göre, SOS'un GA'ya göre maksimum aşım bakımından $\% 2,1$, yerleşme zamanı açısından ise GA'ya göre $\% 25$, Z-N'e göre de $\% 73$ daha iyi performansa sahip olduğu anlaşılmıştır. Öte yandan, GA ile SOS'un yükselme zamanlarının birbirine eşit olduğu, bu sonucun ise Z-N'e göre \%42,9 daha iyi olduğu gözlemlenmiştir. Gürbüzlük testinde nominal değerlerden ortalama sapma miktarını \%18,2 olarak hesaplanması, SOS tabanlı PI denetleyicinin gürbüz olduğunu göstermiş ve belirlenen aralıktaki değişik parametre durumundan çok fazla etkilenmeden istenen denetim davranışını sağladığı görülmüştür. Sonuç olarak sürme sisteminin referans hız izleme performansı ile bozucu etkenlere karşı dayanıklılığı artırılmıştır.
\end{abstract}

Anahtar Kelimeler- DA motoru, PI denetleyici, simbiyotik organizmalar arama algoritması, genetik algoritma, ziegler-nichols, optimizasyon

\section{Optimal Setting of PI Parameters for Direct Current Motor Drives by Symbiotic Organisms Search Algorithm}

\begin{abstract}
Owing to their simple control and good torque-speed characteristics in addition to being economical, direct current (DC) motors are important electric machines for both industrial applications and our daily life. Proper parameter setting of proportional+integral (PI) controller used in their control is difficult, as well as holding a strong part for performance and stability of the system. In this study, a new alternative solution based on the robust and powerful symbiotic organisms search (SOS) algorithm is presented for optimization of PI coefficients. Using genetic algorithm (GA) and classical Ziegler-Nichols (Z-N), results following the transient analysis of the obtained responses are compared in terms of rise time, settling time, and maximum overshoot. Moreover, robustness analysis of presented approach is carried out under parameter change. According to obtained simulation results realized by using $\mathrm{C}$ language and real industrial motor parameters, it is inferred that SOS has better performance than GA by 2,1\% for maximum overshoot, and by $25 \%$ and $73 \%$ than GA and Z-N for settling time. On the other hand, it is observed that the rise times of GA and SOS are equal, which is better than Z-N by $42,9 \%$. In the robustness test, computing the average deviation from the nominal values as $18,2 \%$ shows that SOS-based PI controller is robust, and it is found that it provides the desired control behaviour without being significantly affected by the parameter change in the specified range. Lastly, the drive system's speed reference tracking performance and robustness against disturbances are improved.
\end{abstract}

Keywords - DC motor, PI controller, symbiotic organisms search algorithm, genetic algorithm, ziegler-nichols, optimization 


\section{GİRIŞ (INTRODUCTION)}

DA motorları denetimlerinin kolaylığı, iyi derecedeki moment-hız karakteristikleri ile düşük maliyetli çözüm sunmalarından dolayı ev aletlerinden endüstriyel tip uygulamalara kadar birçok alanda yüzyılı aşkın bir süredir kullanılmaktadırlar [1, 2]. Bu tip motorların hız denetimi ilk kez Ward Leonard tarafindan gerilim ayarı ile 1891 yılında gerçekleştirilmiştir [3]. Geleneksel alternatif akım (AA) motorlarının geniş bir aralıkta hız denetimlerine yönelik çalışmalar gerçekleştirilmesine rağmen DA motorlarında doğal olan bu özellik hem pratiklik hem de esneklik açısından AA motorları ile henüz elde edilememiştir [4]. Sabit mıknatıslı fırçasız DA motorları, hem geleneksel DA motorları ile benzer performans göstermeleri hem de komütatör ve firça gibi teçhizatlara ihtiyaç göstermemeleri nedeniyle popülerlik kazanmışlardır. Bu tarz motorlar firçalı DA motorlarına verilen önemi, ilgiliyi azaltsa da günümüz teknolojisiyle düşündüğümüzde DA motorlarının yerini tamamıyla almaları mümkün değildir. Zira firçasız servo motorların üretim maliyetleri ile işletme giderleri nispeten daha fazladır. Bu nedenle geleneksel DA motorları endüstriyel uygulamalardaki rekabetçi konumunu sürdürmektedirler ve bu motorlara olan ihtiyaç gelecekte de devam edecektir [5].

DA motorlarının hız denetimleri için çok çeşitli denetim teknikleri bulunmaktadır. $\mathrm{Bu}$ tekniklerden bazıları PI denetleyiciler, model bazlı denetleyiciler, bulanık mantık denetleyiciler, yapay sinir ağlarına dayalı denetleyiciler, sinirsel bulanık denetim vb. şeklindedir. Her bir denetim yaklaşımının kendine has avantajları ile dezavantajları bulunmaktadır. Hiç şüphesiz bunlar içerisinde en yaygını, uygulaması en basit ve düşük maliyetli olanı PI denetleyicilerdir [6, 7]. Son yıllara ait bir çalışmada endüstriyel uygulamalardaki denetim organlarının çoğunun PI/PID tipinden olduğu belirtilmiştir [8]. PI parametrelerinin doğru bir şekilde ayarı denetimi gerçekleştirilen sistemin performansı açısından önemli bir yere sahiptir. Sistem modeline bağlı olan bu parametreler, sistemin birim basamak cevabı analiz edilerek uzun yıllar boyunca Z-N yöntemi ile belirlenmiştir. Pratikte ise bu işlem için operatör yardımına başvurulur. Operatör sistem üzerinde çok çeşitli deneyler yaparak deneme yanılma yöntemi ile PI parametrelerinin ne olması gerektiğine karar verir. $\mathrm{Bu}$ işlem zor olmakla birlikte zaman açısından da pahalıdır. Ayrıca sürecin sonunda elde edilecek parametrelerin optimal olması garanti edilemez. Son zamanlarda çok sayıda meta-sezgisel algoritma optimal PI denetleyici elde etmek için kullanılmış, algoritmaların performansına bağlı olarak farklı derecelerde başarılar elde edilmiştir. Böylece operatörün görevi, algoritmalara devredilerek birçok denetleyici parametresi belli bir sistematiğe göre değerlendirilir ve potansiyel çözüm uzayı içerisindeki en iyisi ya da en iyiye yakın olanı elde edilir. Üstelik bu işlem daha kısa sürede tamamlanır. [6, 7, 913]'de verilen çalışmalar bu alanda son zamanlarda gerçekleştirilen çalışmalardan bazılarıdır. PI denetleyiciler uygulamada büyük ilgi gördüklerinden, bu çalışmada bu denetleyicilerin performanslarının iyileştirilmesi için yakın zamanda ortaya konulan, simbiyotik organizmalar arama algoritması olarak adlandırılan güçlü optimizasyon tekniğinden faydalanılmıştır. SOS kullanılarak test edilen denetim sisteminin performansını iyileştirecek daha iyi denetleyici parametrelerin elde edilmesi bu çalışmanın temel motivasyonunu oluşturmaktadır. Elde edilen denetleyici parametrelerin optimal olması ya da küresel optimum çözüme nazaran çok küçük bir hataya sahip olmaları beklenmektedir.

SOS algoritması 2014 yılında ortaya konulan basit ve güçlü meta-sezgisel yeni bir algoritmadır. $\mathrm{Bu}$ algoritma yaşamlarını sürdürmek ve çoğalmak için ekosistemdeki organizmalar tarafından benimsenen simbiyotik etkileşim stratejilerini taklit etmektedir [14]. Popülasyon tabanlı algoritmalara benzer olarak SOS algoritması, başlangıçta çözüm uzayında dağınık halde bulunan noktalar ile arama işlemine başlayarak, kendine özgü adımlarıyla küresel en iyi çözüme doğru ilerler. SOS'u diğer algoritmalardan ayıran en önemli özellik algoritmanın işleyişinde algoritmik parametreye ihtiyaç göstermemesidir. $\mathrm{Bu}$ ise algoritmanın performans kararlılığı iyileştirmektedir. GA, Darwin'in evrim teorisi prensipleri 1şı ğında rastlantısal araştırma metotlarını kullanır [15]. GA'ların verimli ve etkin arama gerektiren problemlere geçerli bir yaklaşım sunması ile birlikte karmaşık arama uzayında güçlü arama yeteneğine sahip oluşu hem teorik hem de deneysel olarak kanıtlanmıştır [16].

Bu çalışmada ilk defa DA motoru kapalı çevrim hız denetim sistemindeki PI parametrelerinin optimal ayarı için SOS algoritması önerilmektedir. C programlama dili kullanılarak hazırlanan benzetimde denetleyici parametreleri motorun değişken hız ve değişken yüklü durumlarda çalışması dikkate alınarak elde edilmiştir. Ayrıca değişik parametre durumu da hesaba katılmıştır. $\mathrm{Bu}$ manada optimizayon sürecinde endüvi direnci ile endüktansı $\% \pm 20$ aralığında değiştirilmiştir. Ortaya konulan SOS tabanlı PI denetleyici performansının değerlendirilmesi için elde edilen sonuçlar sezgisel bir yöntem olan Z-N yöntemi ve literatürde yaygın olarak kullanılan GA ile karşılaştırılmıştır. Çeşitli koşullarda gerçekleştirilen benzetim çalışmalarının sonucunda önerilen yaklaşımın bu çalışmada ele alınan optimizasyon probleminde daha iyi sonuçlar ürettiği ve böylece denetleyici performansını artırarak sistemin dinamik tepkisinde iyileşmeler sağladığı gözlemlenmiştir.

Çalışmada 2. Bölümde SOS ile ilgili özet bilgi verildikten sonra 3. Bölümde SOS kullanılarak PI katsayılarının nasıl ayarlandığ1 açıklanmıştır. 4. Bölümde üç yöntemden faydalanılarak elde edilen benzetim sonuçları karşılaştırmalı olarak verilmiştir. Son bölümde ise çalışmanın genel değerlendirilmesi yapılmıştır. 


\section{SIMBIYOTIK ORGANIZMALAR ARAMA ALGORITMASI (SYMBIOTIC ORGANISMS SEARCH ALGORITHM)}

Son 20 yılda yapay zekâ, hesaplamalı zekâ, matematiksel programlama vb. dâhil olmak üzere birçok bilim alanında meta-sezgisellerin kullanımında büyük gelişmeler kaydedilmiştir. Çoğu doğa olaylarından esinlenerek geliştirilen meta-sezgisel algoritmalar arasında örneğin, en popüler algoritmalarından biri olarak Darwin evrim teorisinden esinlenen GA doğal evrim sürecini taklit etmektedir [17]. Eberhart ve Kennedy tarafından önerilen Parçacık Sürüsü Optimizasyonunda (PSO) yiyeceklerini arayan kuş sürülerinin sosyal davranışından esinlenilmiştir [18]. Karaboğa tarafindan geliştirilen Yapay Ar1 Kolonisi (ABC) arı sürüsünün avcılık davranışını taklit etmektedir [19]. ABC algoritmasında olduğu gibi Karınca Kolonisi (AC) de karınca kolonilerinin yiyecek arama davranışından esinlenen diğer bir optimizasyon algoritmasıdır [20]. Yer Çekimi Arama Algoritmas1 (GSA) ise Newton'un 'Evrendeki her parçacık kendisinden başka her parçacığı çeker" kuralına dayalı olarak ortaya konulmuştur [21]. Bu algoritmalardan yakın zamanda geliştirilen, basit ve güçlü yapısı ile dikkat çeken SOS, bir ekosistemde birlikte yaşayan simbiyotik organizmalar arasında gerçekleşen simbiyotik etkileşimleri taklit etmektedir. SOS'u diğer meta-sezgisellerden ayıran en önemli özellik algoritmanın performansı açısından öneme sahip olan algoritmik parametrelere ihtiyaç göstermemesidir. Bundan dolayı SOS performansı farklı problemlere karşı tutarlılık gösterir [14].

SOS popülasyon tabanlı bir algoritma olup, arama işlemine ekosistem adı verilen ve genellikle rastgele oluşturulan başlangıç popülasyonu ile başlar. Ekosistemdeki her bir çözüme organizma adı verilir ve organizmalardan her biri probleme belli derecedeki çözümü ifade eder. SOS algoritması doğada en yaygın biçimde görülen üç simbiyotik ilişkiden yararlanılarak geliştirilmiştir. $\mathrm{Bu}$ ilişkiler sırasıyla mutualizm, kommensalizm ve parazitizmdir [22]. Her bir faz organizmanın hareketini ve başka bir organizmanın yerine geçip geçmeyeceğine karar verir. Mutualizm iki ayrı türün karşılıklı yarar sağladıkları simbiyotik ilişkiyi canlandırır. Kommensalizm iki organizmadan birinin yarar gördüğü diğerinin ise ne yarar ne de zarar gördüğü simbiyotik ilişkidir. Parazitizm ise iki organizmadan birinin yarar görürken diğerinin zarar gördüğü simbiyotik ilişkidir [23]. Tüm fazlar tamamlandıktan sonra algoritmanın bir sonraki iterasyonu başlar ve bu süreç sonlandırma kriterleri sağlanıncaya kadar devam eder. $\mathrm{Bu}$ açıklamalardan sonra algoritmanın sözde kodu eco_size ekosistemdeki organizma sayıs1, $f$ minimizasyonu gerçekleştirilen amaç fonksiyonu olmak üzere Şekil 1'de verilmiştir.

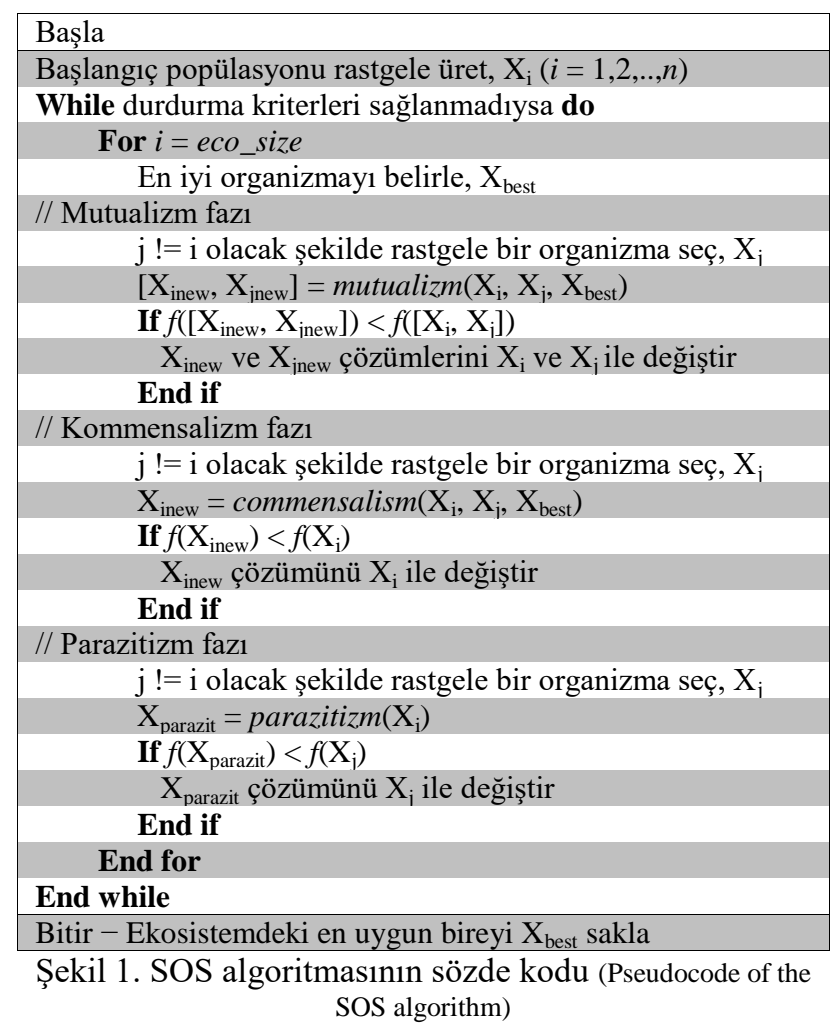

\section{SOS TABANLI PI DENETLEYICI TASARIMI (DESIGN OF THE SOS-BASED PI CONTROLLER)}

Optimizasyon işlemi için uygun bir benzetim modeline ihtiyaç olduğu için çalışmada öncelikle DA-DA dönüştürücü, PI denetleyici ve motor modeli oluşturularak uygun şekilde birleştirilmiş ve DA motoru kapalı çevrim sürme sistemi için tam model elde edilmiștir. Benzetim çalışmalarında $\mathrm{C}$ programlama dili tercih edilmiştir. Sabit mıknatıslı DA motoru için [10]'da verilen model kullanılmıştır. PI denetim kuralı olarak aşağıdaki eşitliklerden faydalanılmıştır.

$i^{*}=K_{p}\left(\omega^{*}-\omega\right)+K_{i} \int\left(\omega^{*}-\omega\right) d t$

Eş. 1 'de $i^{*}$ denetim akımı ya da referans akım, $K_{p}$ oransal kazanç, $K_{i}$ integral kazanç, $\omega^{*}$ referans hız ve $\omega$ gerçek rotor hızını göstermektedir. Eşitliğin her iki tarafının sayısal türevi alındığında Eş. 2 elde edilir. Bu eşitlik ile PI denetleyicilerin çıkışının doyumu olarak ifade edilen integral wind-up probleminin önüne geçilmesi amaçlanmıştır.

$i^{*}(k)-i^{*}(k-1)=K_{p}[e(k)-e(k-1)]+K_{i} T e(k)$

Eş. 2'de $T$ örnekleme aralığı, $e$ hata değeri, .(k) ve . $(k-1)$ sırasıyla ilgili değişkenin o anki ve bir önceki değerini göstermektedir. Eşitlikten görüldüğü gibi denetleyici çıkışı bu haliyle denetim akımındaki değişimi üretmektedir. Bu değişim, bir önceki bir önceki denetim 
akımı ile toplanarak sürme sistemi için nihai denetim akımı değeri Eş. 3'deki gibi elde edilir.

$$
i^{*}(k)=i^{*}(k-1)+\Delta i^{*}(k)
$$

Eş. 2'de görülen denetim kuralındaki $K_{p}$ ve $K_{i}$ denetleyici parametrelerinin SOS algoritması kullanılarak optimizasyonu bu çalışmanın temel amacıdır.

SOS algoritmasının başlangıcında, PI parametrelerinden oluşan bir dizi organizma $0 \leq K_{p}, K_{i} \leq 20$ olacak şekilde rastgele üretilmiştir. PI denetleyici performansı referans hız, yük momenti ve parametre değişimlerine karşı hassas olduğu için denetleyici parametrelerinin optimizasyonu yalnızca belli bir motor çalışma durumu dikkate alınarak gerçekleştirilmemiştir. Bunun yerine optimizasyon sırasında, izin verilen sınırlar dahilinde değişik hız referansları, yüksüz durumdan tam yüklü durum ve parametre duyarlılığı için endüvi direnci ile endüktansının $\% \pm 20$ aralığında değiştiği durumlar hesaba katılmıştır. Her bir organizma ya da aday denetleyici, kapalı çevrim sürme sistemine uygulandıktan sonra sistemin bu denetleyici ile değişik koşullarda belli bir süre benzetimi gerçekleştirilmiş ve çeşitli hız tepkileri elde edilmiştir. Beklendiği üzere her bir denetleyici, yükselme zamanı, yerleşme zamanı, aşım miktarı ve kalıcı durum performansı açısından farklı tepkilere neden olacaktır. Ekosistemdeki denetleyicilerin uygunluğunun değerlendirilmesi için ISE (Integral Squared Error) ve IAE (Integral Absolute Error) performans kriterleri birleştirilerek elde edilen amaç fonksiyonu Eş. 4'te verilmiştir.

$$
P_{k}=\alpha \int_{0}^{t} e_{k}^{2} d t+\beta \int_{0}^{t}\left|e_{k}\right| d t
$$

Burada, $e_{k} k$. organizma için referans hız ile gerçek hız arasındaki hata miktarı, $\alpha$ ve $\beta$ ise ağırlık katsayılarıdır. ISE zamana göre hatanın karesini toplandığı için ISE'nin azaltılmasına yönelik denetim sistemleri büyük hataları hızlı bir şekilde yok ederek tepki hızında iyileşme sağlarken, bu durum aşım ve osilasyona neden olur. IAE ise zamana göre hatanın mutlak değerini toplar. ISE'e göre daha yavaş bir tepkiye neden olurken, aşım ve osilasyonda iyileşme sağlar. Çalışmadaki amaç, çok küçük bir aşım ile hızlı bir cevap eğrisinin elde edilmesi olduğundan ağırlık katsayılarının sırasıyla 0,65 ve 0,35 olarak ayarlanması olumlu sonuçlar üretmiştir.

Her bir organizmanın değişik çalışma koşullarına göre genel performansı Eş. 4 kullanılarak hesaplandıktan sonra tipik SOS fazları ile güncellenmek üzere optimizasyon modülüne geri gönderilirler. Organizmaların bu şekilde sırayla kapalı çevrim sürme sistemine uygulanması ve ardından optimizasyon modülüne geri gönderilmeleri süreci maksimum iterasyon sayısına kadar tekrar etmektedir. Bu durum Şekil 2'deki blok diyagramı ile gösterilmiştir.

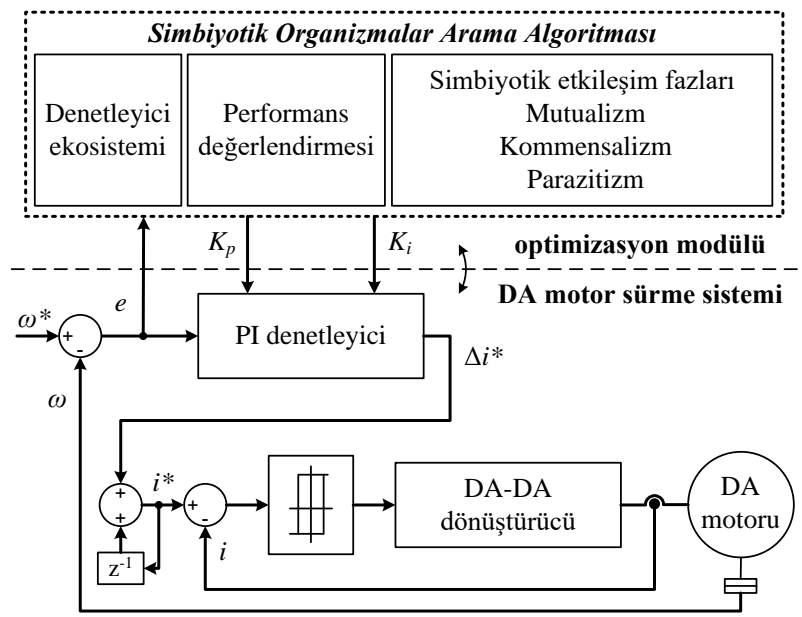

Şekil 2. DA motor sürücüsü için SOS uygulaması (SOS implementation for the DC motor drive)

\section{BENZETIM SONUÇLARI (SIMULATION RESULTS)}

Önerilen yaklaşım uygunluğunu ve performansını test etmek için C ortamında GA ve Z-N yöntemi ile karşılaştırmalı olarak çeşitli benzetim çalışmaları gerçekleştirilmiştir. Benzetim çalışmalarında kullanılan sabit miknatıslı DA motor parametreleri Sanyo Denki firmasının ürettiği, R730T-042EL7 model motora aittir. Bu parametreler Tablo 1'de verilmiştir.

Tablo 1. DA motor parametreleri (DC motor parameters)

\begin{tabular}{|l|l|}
\hline \multicolumn{1}{|c|}{ Parametreler } & \multicolumn{1}{c|}{ Değer } \\
\hline Anma gücü & $300 \mathrm{~W}$ \\
\hline Anma gerilimi & $80 \mathrm{~V}$ \\
\hline Anma akımı & $4,8 \mathrm{~A}$ \\
\hline Endüvi direnci & $1,75 \Omega$ \\
\hline Elektriksel zaman sabiti & $1,5 \mathrm{~ms}$ \\
\hline Gerilim sabiti & $28,6 \mathrm{~V} / \mathrm{kmin}^{-1}$ \\
\hline Anma hızı & $2500 \mathrm{~d} / \mathrm{d}$ \\
\hline Eylemsizlik momenti & $5,8 \cdot 10^{-4} \mathrm{~kg} \cdot \mathrm{m}^{2}$ \\
\hline
\end{tabular}

GA'daki popülasyon boyutu, SOS'daki ekosistem boyutuna eşit olup 30 olarak ayarlanmıştır. Dışlanma oranı ile mutasyon oranı GA'da sirasiyla 0,42 ve 0,31 'dir. Doğal seçim mekanizması sıraya dayalı rulet tekerleğine dayalı olup, çaprazlama tekniği olarak üniform yöntemi kullanılmıştır. GA'da aynı zamanda popülasyondaki elit birey sonraki nesillere değişiklik yapılmadan aktarılmıştır. Z-N, GA ve SOS metodunun DA motor sürme sistemine uygulanmasiyla elde edilen PI parametreleri Tablo 2'de görülmektedir.

Tablo 2. Elde edilen PI parametreleri (Obtained PI parameters)

\begin{tabular}{|c|c|c|c|}
\hline \multirow{2}{*}{ Parametreler } & \multicolumn{3}{|c|}{ Yöntem } \\
\cline { 2 - 4 } & $Z-N$ & $G A$ & $S O S$ \\
\hline
\end{tabular}




\begin{tabular}{|c|c|c|c|}
\hline$K_{p}$ & 0,415 & 0,198 & 0,265 \\
\hline$K_{i}$ & 10,523 & 17,031 & 19,998 \\
\hline
\end{tabular}

Şekil 3'de GA ve SOS algoritması kullanılarak çalışmadaki test sistemi için elde edilen çözümlerin ilk 250 iterasyon için yakınsama eğrileri görülmektedir. Şekilde ilk keskin düşüşün ardından GA'da popülasyonun en iyi çözümü neredeyse sabit bir değerde kaldığ 1 , SOS algoritmasının ise optimal nokta etrafında daha iyi çözümü elde etme başarısına sahip olduğu görülmüştür. Eğriler, farklı çalışma koşullarında hesaplanan Eş. 4'ün ortalama değerini gösterdikleri için her iki algoritma ile elde edilen nihai çözümler arasında büyük fark görülmemektedir.

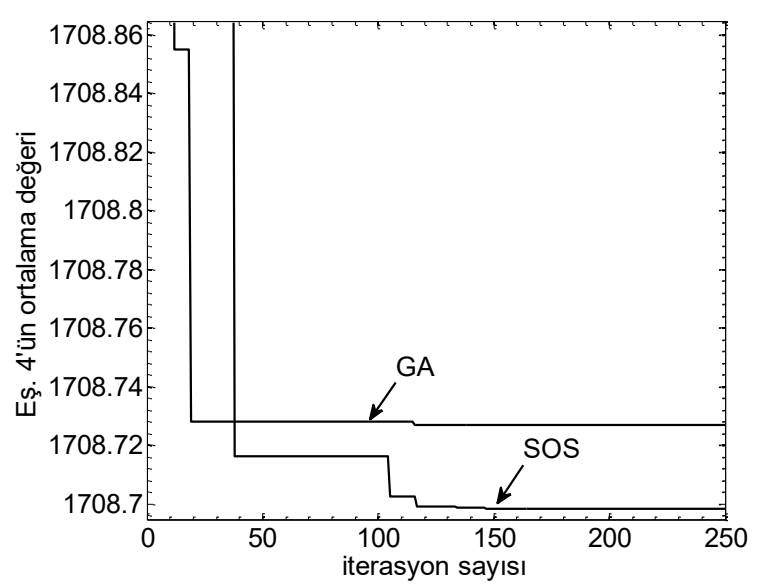

Şekil 3. GA ve SOS ile elde edilen çözümlerin yakınsama eğrileri (Convergence curves of solutions obtained by GA and SOS)

Benzetim aşamasında DA motorunun aşağıda verilen dört durumda çalışması test edilmiştir.

1. $1500 \mathrm{~d} / \mathrm{d}$ referans hız ve yüksüz durumda

2. $2000 \mathrm{~d} / \mathrm{d}$ referans hız ve değişken yüklü durumda

3. Değişken referans hız ve yüklü durumda

4. Değişken parametre durumunda

Motorun Z-N, GA ve SOS ile elde edilen PI parametreleriyle 1. durumda çalışması esnasındaki motor hız tepkileri Şekil 4'te görülmektedir. Edilen sonuçlara göre her üç durumda da kalıcı durum hatası görülmemiştir. Z-N yöntemi ile ayarlanan PI denetleyici olumlu şekilde aşıma neden olmamasına rağmen tepki hızı düşüktür. GA'da ise yerleşme zamanı iyileştirilmiş ancak bu durum aşıma neden olmuştur. Elde edilen bu sonuçlar, SOS ile elde edilenlerle karşılaştırıldığında, SOS her ikisinin de olumlu özelliklerini birleştirerek, yerleşme zamanını daha da kısaltırken maksimum aşım miktarını da başarılı şekilde düşürmüştür.

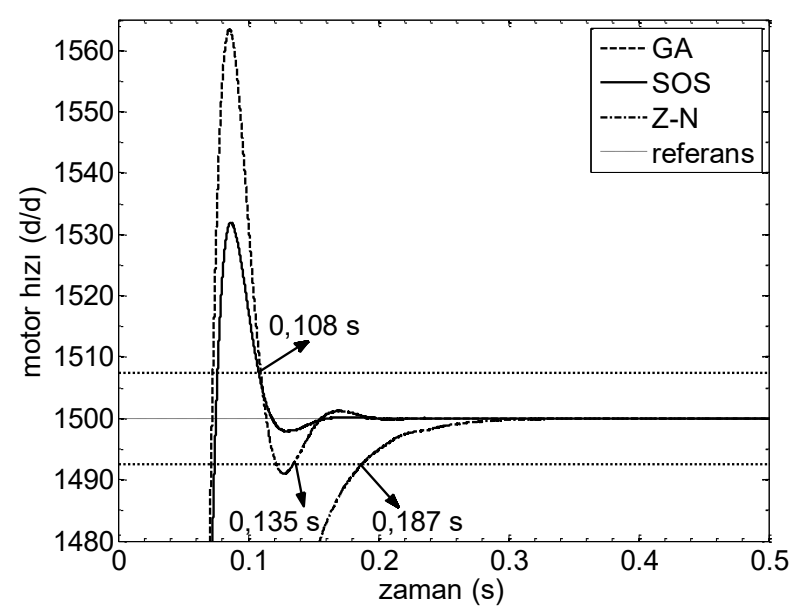

Şekil 4. Motorun 1. durumda çalışması esnasındaki hız tepkileri (Speed responses under case 1)

Geçici durum analizi, sistemin başlangıcından kalıcı durum zamanına kadarki olan davranışsal özellikleri ile ilişkilidir. Buna göre Şekil 4'te verilen tepkilerin geçici durum analizleri yapıldığında elde edilen sayısal sonuçlar Tablo 3'de verilmiştir. Koyu renkli sayılar karşılaştırmalı olarak minimum değerleri göstermektedirler.

Tablo 3. DA motor denetim sisteminin geçici durum analiz sonuçları (Results of the transient response analysis of the DC

\begin{tabular}{|c|c|c|c|}
\hline & $\begin{array}{c}\text { Maksimum } \\
\text { aşım, \% }\end{array}$ & $\begin{array}{c}\text { Yerleşme zamanı } \\
(\% 1 \text { band) (s) }\end{array}$ & $\begin{array}{c}\text { Yükselme } \\
\text { zamanı (s) }\end{array}$ \\
\hline Z-N & $\mathbf{0 , 0 0}$ & 0,187 & 0,080 \\
\hline GA & 4,20 & 0,135 & $\mathbf{0 , 0 5 6}$ \\
\hline SOS & 2,12 & $\mathbf{0 , 1 0 8}$ & $\mathbf{0 , 0 5 6}$ \\
\hline
\end{tabular}

Tabloya göre maksimum aşım bakımından SOS algoritması GA'ya göre \%2,1 daha iyi sonuç elde etmiştir. Yerleşme zamanı açısından ise GA'ya göre \%25, Z-N'e göre de \%73 daha iyi performansa sahiptir. Öte yandan, GA ile SOS'un yükselme zamanları birbirine eşit olup, ZN'e göre \%42,9 daha iyi oldukları görülmektedir.

Önerilen yaklaşımın bozucu yük değişimlerine karş1 tepkisinin değerlendirilmesi için motor $2000 \mathrm{~d} / \mathrm{d}$ ile yüksüz olarak çalışırken miline $t=1 \mathrm{~s}$ 'de anma yükü bindirilmiş, motor bu şartlarda $1 \mathrm{~s}$ çalıştıktan sonra $t=$ 2 s'de yük kaldırılmıştır. Elde edilen sonuçlar Şekil 5 'te karşılaştırmalı olarak verilmiştir. Hızdaki toparlanma süre önerilen yöntemde en düşük iken, geçici durumda oluşan hız salınımı Z-N ile elde salınıma yakındır. 


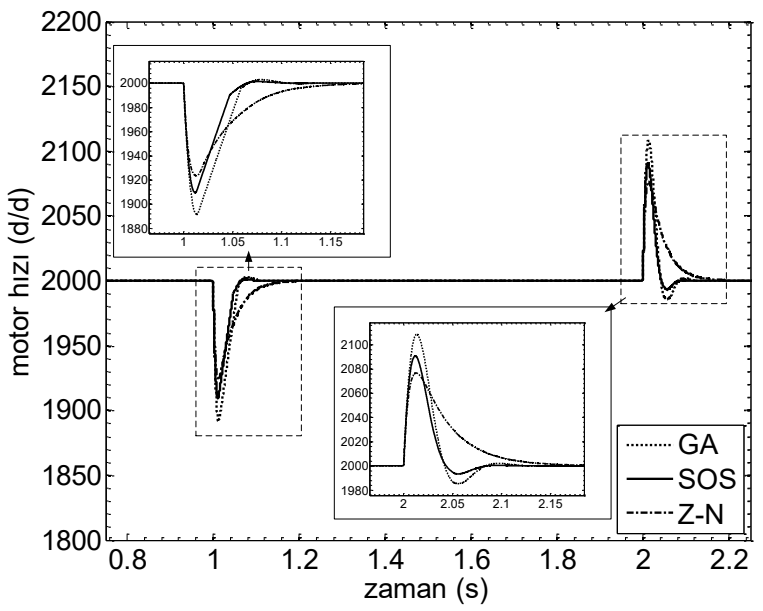

Şekil 5. Motorun 2. durumda çalışması esnasındaki hız tepkileri (Speed responses under case 2)

Şekil 6'da denetleyicilerin sabit yük altında değişken hız referanslarını izleme performansı ile ilgili elde edilen sonuçlar görülmektedir. Bu çalışma durumu için değişken referans hiz $0 \mathrm{~s}$ ile $0,2 \mathrm{~s}$ arasinda $0 \mathrm{~d} / \mathrm{d}, 0,2 \mathrm{~s}$ ile $0,6 \mathrm{~s}$ arasinda $1000 \mathrm{~d} / \mathrm{d}, 0,6 \mathrm{~s}$ ile $1 \mathrm{~s}$ arasinda $2000 \mathrm{~d} / \mathrm{d}, 1 \mathrm{~s}$ ile $1,4 \mathrm{~s}$ arasında tekrar $0 \mathrm{~d} / \mathrm{d}$ ve sonrasinda $500 \mathrm{~d} / \mathrm{d}$ olarak verilmiştir. Elde edilen sonuçlara göre, her üç durumda da motorun kalıcı durumda referans hızı izlediği görülmüştür. SOS ile edilen sonuç, Z-N ile karşılaştırıldığında yerleşme ve yükselme zamanının önemli derece iyileştiği, GA ile karşılaştırıldığında ise aşım miktarının başarılı bir şekilde azaltıldığ görülmüştür. Sonuç olarak, her çalışmada küçük bir aşımdan sonra referans hıza oturan, dinamik tepkisi iyi bir hız eğrisi elde edilmiştir.

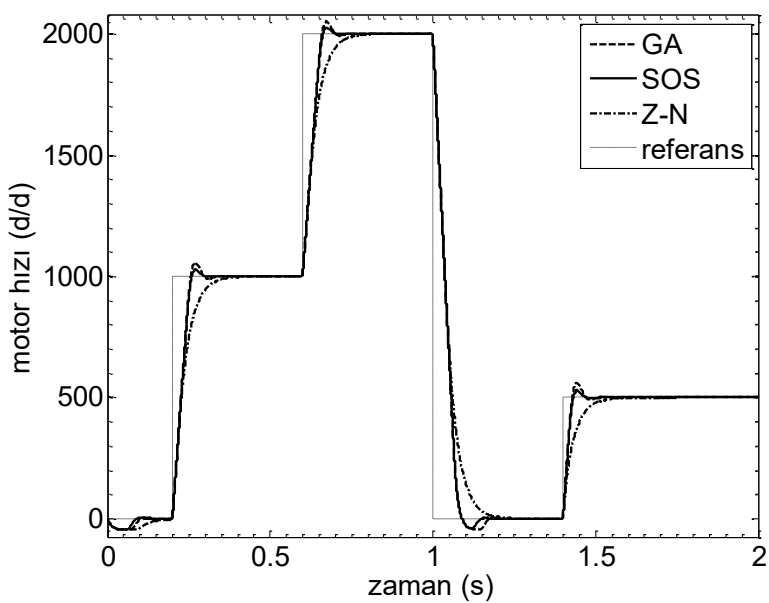

Şekil 6. Motorun 3. durumda çalışması esnasındaki hız tepkileri (Speed responses under case 3)

SOS ile ayarlanan DA motor denetim sisteminin gürbüzlük analizi için motor modelinde kullanılan eylemsizlik moment katsayısı $J$ ile sürtünme katsayısı $B$ sırasıyla $-\% 25,-\% 50$ ve $\% 25$ aralığında değiştirilerek elde edilen sonuçlar Şekil 7 ve Tablo 4'de verilmiştir. Ayrıca nominal değerlerden maksimum sapma miktarı birim cinsinden ve yüzde cinsinden Tablo 5 'te verilmiştir. Örneğin, $J$ için yerleşme zamanı nominal değerinden maksimum $0,088 \mathrm{~s}$ sapmış, bu durum yüzde cinsinden \%51,2 olarak hesaplanmıştır. Öte yandan, $B$ için yükselme zamanının nominal değerinden maksimum sapma miktarı 6 ms olarak elde edilmiş, bu durum yüzde cinsinden \%5,4 olarak hesaplanmıştır. Her iki parametre için ortalama yüzde sapma maksimum aşım için $\% 0,53$, yerleşme zamanı için \%26,7, yükselme zamanı için \%27,4 ve tepe zamanı için \%18,4 olarak elde edilmiştir. Tüm parametreler ve performans kriterleri dikkate alınarak ortalama sapma miktarının \%18,2 olarak hesaplanması, SOS tabanlı PI denetleyicinin gürbüz olduğunu ve $J$ ile $B$ parametrelerinin belirlenen aralıktaki değişimlerinden çok fazla etkilenmeden, istenen denetim davranışını sağladığ görülmüştür.

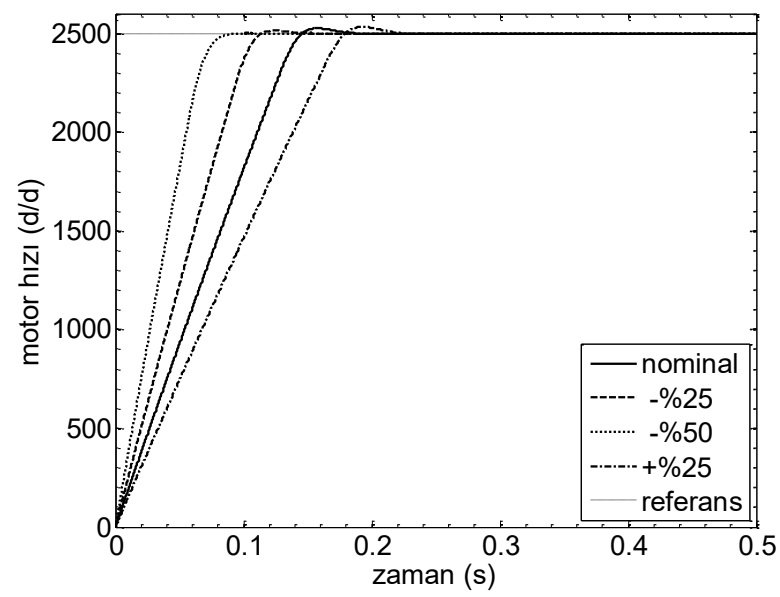

(a)

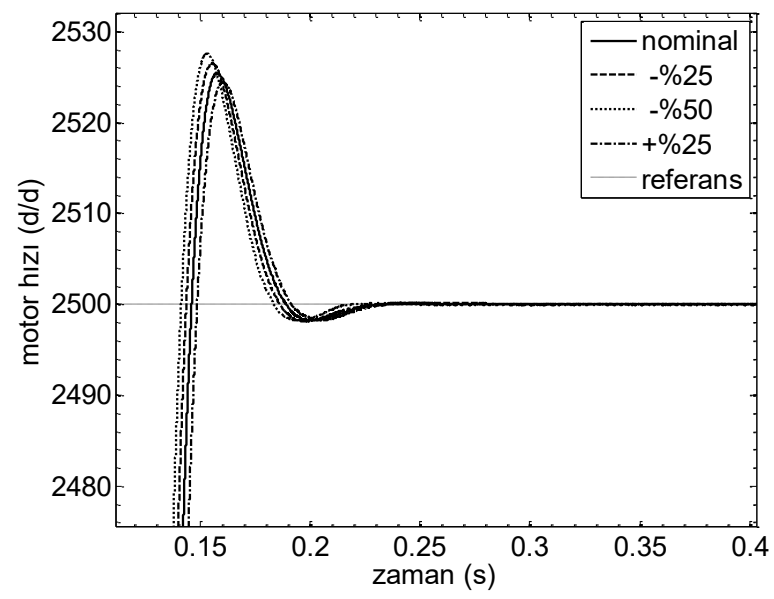

(b)

Şekil 7. Değişken parametre durumunda hız tepkileri (a) $J$ değişimi (b) $B$ değişimi (Speed responses under parameter change (a) change of $J$ (b) change of $B$ ) 
Tablo 4. SOS ile ayarlanan DA motor denetim sisteminin gürbüzlük analizi için elde edilen sonuçlar (Obtained results of robustness analysis for the DC motor control system tuned by SOS)

\begin{tabular}{|c|c|c|c|c|c|}
\hline Parametre & $\begin{array}{l}\text { Değişim } \\
\text { oran1, \% }\end{array}$ & $\begin{array}{l}\text { Maksimum } \\
\text { aşım, \% }\end{array}$ & $\begin{array}{c}\text { Yerleşme } \\
\text { zaman1 } \\
(\% 1 \text { band }),{ }^{a}\end{array}$ & $\begin{array}{l}\text { Yükselme } \\
\text { zamanı, }\end{array}$ & $\begin{array}{c}\text { Tepe } \\
\text { zaman1, }^{c}\end{array}$ \\
\hline \multirow{4}{*}{$\begin{array}{c}J \text { (Eylemsizlik } \\
\text { momenti) }\end{array}$} & -50 & 0,040 & 0,084 & 0,056 & 0,103 \\
\hline & -25 & 0,561 & 0,128 & 0,083 & 0,124 \\
\hline & Nominal & 1,000 & 0,172 & 0,111 & 0,157 \\
\hline & 25 & 1,322 & 0,211 & 0,140 & 0,193 \\
\hline \multirow{4}{*}{$\begin{array}{c}B \text { (Sürtünme } \\
\text { katsayısı) }\end{array}$} & -50 & 1,120 & 0,168 & 0,105 & 0,153 \\
\hline & -25 & 1,080 & 0,170 & 0,106 & 0,155 \\
\hline & Nominal & 1,000 & 0,172 & 0,111 & 0,157 \\
\hline & 25 & 0,960 & 0,174 & 0,112 & 0,160 \\
\hline
\end{tabular}

${ }^{\mathrm{a}}$ Tepkinin $t=0$ 'dan \%1'lik band içerisine girinceye kadar geçen süre

${ }^{\mathrm{b}}$ Tepkinin referans değerin \%10'nundan \%90'nına ulaşıncaya kadar geçen süre

${ }^{c}$ Tepkinin maksimum noktaya ulaştığında geçen süre

Tablo 5. Test edilen sistem için nominal değerlerden birim ve yüzde cinsinden maksimum sapma miktarları (Amounts of maximum deviations from the nominal values in unit and percentage for the tested system)

\begin{tabular}{|c|l|c|c|}
\multicolumn{2}{|c|}{ maximum deviations from the nominal values in unit and percentage for the tested system) } \\
\hline \multirow{3}{*}{$\begin{array}{c}J \text { (Eylemsizlik } \\
\text { momenti) }\end{array}$} & Performans kriterleri & Maksimum sapma & Maksimum sapma, \% \\
\cline { 2 - 4 } & Yerleşme zamanı & $24 \mathrm{~d} / \mathrm{d}$ & 0,95 \\
\cline { 2 - 4 } & Yükselme zamanı & $0,088 \mathrm{~s}$ & 51,2 \\
\cline { 2 - 4 } & Tepe zamanı & $0,055 \mathrm{~s}$ & 49,5 \\
\hline \multirow{3}{*}{$\begin{array}{c}\text { B (Sürtünme } \\
\text { katsayısi) }\end{array}$} & Maksimum aşım & $0,054 \mathrm{~s}$ & 34,3 \\
\cline { 2 - 4 } & Yerleşme zamanı & $28 \mathrm{~d} / \mathrm{d}$ & 0,11 \\
\cline { 2 - 4 } & Yükselme zamanı & $0,004 \mathrm{~s}$ & 2,32 \\
\cline { 2 - 4 } & Tepe zamanı & $0,006 \mathrm{~s}$ & 5,40 \\
\hline
\end{tabular}

\section{SONUÇLAR (CONLUSIONS)}

$\mathrm{Bu}$ çalışmada yeni bir optimizasyon tekniği olarak SOS algoritması, DA motor hız denetiminde kullanılan PI parametreleri $K_{p}$ ve $K_{i}$ 'nin optimizasyonu için kullanılmıştır. Optimizasyon sonrasındaki PI denetleyicinin DA motor denetim sistemindeki performansının test edilmesi için sezgisel bir yöntem olan Z-N yöntemi ile popülasyon tabanlı, güçlü bir algoritma özelliğine sahip GA'dan faydalanılarak değişken hız referansı, değişken yük durumlarında karşılaştırmalı benzetim çalışmaları gerçekleştirilmiştir. Sonuçların elde edilmesinde geçici durum analizi yapılmış ve elde edilen sonuçlar maksimum aşım, yerleşme zamanı ve yükselme zamanı gibi performans kriterleri açısından birbirleriyle karşılaştırılmıştır. Ek olarak, gürbüzlük için önerilen yaklaşım ile test edilen sistemdeki $J$ ve $B$ parametreleri $-\% 25,-\% 50$ ve $\% 25$ aralığında değiştirilerek sistemin bu parametre değişimlerinden ne derece etkilendiği araştırılmıştır. Benzetim sonuçlarına göre, SOS algoritmasının DA motor denetim sistemine başarılı bir şekilde uygulanarak daha iyi PI parametrelerini bulduğu, bu sayede denetim performansının iyileştiği görülmüştür.
Ortaya konulan yaklaşımın yenilikçi yönleri aşağıdaki gibi sıralanabilir.

1) PI denetleyici tasarımının iyileştirilmesine yönelik güçlü, programlanması basit yeni bir alternatif çözüm sunulmuştur.

2) DA motor hiz denetim sisteminde kullanılan bir PI denetleyiciye uygulanan SOS algoritmasının, parametre ayar performansı ve denetim sisteminin gürbüzlüğüne yapmış olduğu katkı geniş kapsamlı ve karşılaştırmalı olarak incelenmiştir.

3) SOS algoritması kendine özgü algoritmik parametreye ihtiyaç göstermediğinden bu parametrelerin doğru ayarlanmamasından kaynaklanan denetleyici katsayılarının yanlış ayarlanma riski çalışmada bulunmamaktadır.

4) Dört farklı senaryoda test edilen SOS-PID denetleyicinin başarılı sonuçlar ürettiği, bundan dolayı çeşitli çalışma koşulları için elde edilen denetleyici parametrelerinin resetlenmesine gerek yoktur.

5) Ortaya konulan yaklaşım, DA motor denetim sisteminden başka diğer farklı denetim sistemlerine de uygulanabilir. 


\section{KAYNAKLAR (REFERENCES)}

[1] V. Léchappé, S. Rouquet, A. González, F. Plestan, JD. León, E. Moulay, A. Glumineau, "Delay estimation and predictive control of uncertain systems with input delay: application to a DC motor", IEEE Trans Ind Electron, 63(9), 5849 - 5857, 2016.

[2] O. Bingöl, S. Pacaci, “A virtual laboratory for fuzzy logic controlled DC motors", International Journal of the Physical Sciences, 5(16), 2493 $-2502,2010$

[3] O. Bingöl, S. Pacaci, "A virtual laboratory for neural network controlled DC motors based on a DC-DC buck converter", Int J Eng Educ, 28(3), 713 - 723, 2012

[4] V. Singh, VK. Garg, "Tuning of PID controller for speed control of DC motor using soft computing techniques - A Review", International Journal of Applied Engineering Research, 9(9), 1141 - 1148, 2016.

[5] ZY. Tong, ZY. Dong, M. Li, “A new entropy Bi-Cepstrum basedmethod for DC motor brush abnormality recognition", IEEE Sensors J, 17(3), $745-754,2017$

[6] M. Demirtaş, "Off-line tuning of a PI speed controller for a permanent magnet brushless DC motor using DSP”, Energ Convers and Manage, 52, $264-273,2011$

[7] PS. Bandaghiri, N. Moradi, SS. Tehrani, "Optimal tuning of PID controller parameters for speed control of DC motor based on world cup optimization algorithm", Tech J Engin \& App Sci, 6(2), 106 - 111 , 2016

[8] A. Tepljakov, EA. Gonzalez, E. Petlenkov, J. Belikov, CA. Monje, I. Petráš, "Incorporation of fractional-order dynamics into an existing PI/PID DC motor control loop", ISA Trans, 60, 262 - 273, 2016.

[9] D. Guhaa, PK. Royb, S. Banerjeea, "Study of differential search algorithm based automatic generation control of an interconnected thermal-thermal system with governor dead-band", Appl Soft Comput, $52,160-175,2017$.

[10] N. Öztürk, "Speed control for DC motor drive based on fuzzy and genetic PI controller-A comparative study", Electronics and Electrical Engineering, 123(7), 43 - 48, 2012.

[11] N. Saridhar, N. Ramrao, MK. Singh, "PID controller auto tuning using ASBO technique", Journal of Control Engineering and Technology, 4(3), $192-204,2014$.
[12] RG. Kanojiya, PM. Meshram, "Optimal tuning of PI controller for speed control of DC motor drive using particle swarm optimization", IEEE International Conference on Advances in Power Conversion and Energy Technologies, Andhra Pradesh, India, 1 - 6, 2012.

[13] H. Gozden, MC. Taplamacioglu, "Comparative performance analysis of artificial bee colony algorithm for automatic voltage regulator (AVR) system”, J Franklin Inst, 348, 1927 - 1946, 2011.

[14] MY. Cheng, D. Prayogo, "Symbiotic organisms search: A new metaheuristic optimization algorithm", Comput Struct, 139, 98 - 112 , 2014

[15] E. Çelik, N. Öztürk, "Genetik algoritma tabanlı geliştirilmiş benzetilmiş tavlama algoritmasıı", Akıllı Sistemlerde Yenilikler ve Uygulamaları Sempozyumu, Düzce, Türkiye, 1 - 6, 2016.

[16] E. Çelik, Üç fazlı fırçasız doğru akım motorları için komütasyon akım salınımının azaltılmasına yönelik yeni bir yaklașım, Doktora Tezi, Gazi Üniversitesi, Fen Bilimleri Enstitüsü, 2016.

[17] M. Mitchell, An Introduction to Genetic Algorithms (Complex Adaptive Systems), The MIT press, 1998

[18] R. Eberhart, J. Kennedy, "A new optimizer using particle swarm theory", IEEE Proceedings of the Sixth International Symposium on Micro Machine and Human Science, Nagoya, Japan, 39 - 43, 1995.

[19] D. Karaboga, An idea based on honey bee swarm for numerical optimization, Techn. Rep. TR06, Erciyes Univ Press, Erciyes, 2005.

[20] M. Dorigo, G. Di Caro, "Ant colony optimization: a new metaheuristic", IEEE Proceedings of the Congress on Evolutionary Computation, Washington, DC, USA, 1470 - 1477, 1999.

[21] E. Rashedi, H. Nezamabadi-Pour, S. Saryazdi, "GSA: a gravitational search algorithm”, Inf Sci, 179(13), 2232 - 2248, 2009.

[22] S. Banerjee, S. Chattopadhyay, "Power optimization of three dimensional turbo code using a novel modified symbiotic organism search (MSOS) algorithm”, Wireless Pers Commun, 92(3), 941 - 968, 2017.

[23] MK. Dosoglu, U. Guvenc, S. Duman, Y. Sonmez, HT. Kahraman, "Symbiotic organisms search optimization algorithm for economic/emission dispatch problem in power systems", Neural Comput Appl, doi:10.1007/s00521-016-2481-7, 2016. 